\title{
Acute hypotension associated with terbutaline nebuliser therapy in a traumatic tetraplegic patient during the spinal shock phase. Case report
}

\author{
BM Soni, S Vaidyanathan, MH Fraser, JHW Watt and KR Krishnan \\ Mersey Regional Spinal Injuries Centre, District General Hospital, Town Lane, Kew, Southport PR8 6PN, UK
}

Acute hypotension was observed during the spinal shock stage of a 35-year-old C3 complete tetraplegic patient after receiving nebulised terbutaline for respiratory therapy. Nine weeks later, when he had recovered from spinal shock, he again received nebulised terbutaline but there was no significant fall in arterial blood pressure. This case illustrates the possibility of a serious degree of hypotension occurring in such patients with this drug.

Keywords: terbutaline; spinal cord injury; spinal shock; hypotension; tetraplegia

\section{Introduction}

With acute cervical spinal cord injury, supraspinal modulation of sympathetic activity is lost, and there are low catecholamines at rest and after reflex maneouvers, which would normally increase the catecholamines even further. ${ }^{1}$ Haemodynamic data have shown a low systemic vascular resistance in acute tetraplegia. ${ }^{2}$ With altered vascular tone, therapeutic agents causing further decrease in peripheral vascular resistance would be expected to have detrimental results. A commonly used bronchodilator, terbutaline has been shown to decrease the mean systemic arterial pressure and the systemic vascular resistance. ${ }^{3}$ Although clinically significant hypotension has not been observed with the use of terbutaline nebuliser therapy in acute tetraplegic patients in our clinical practice during the past decade, we recently encountered this after using terbutaline nebuliser therapy in a traumatic tetraplegic patient during the spinal shock stage, when he had no clinical signs of impaired body fluid volume nor of sepsis, and the urine output was $>80 \mathrm{ml} \mathrm{h}^{-1}$ prior to terbutaline administration.

\section{Case report \\ A 35-year-old male sustained a hyperextension injury of his cervical spine with a fracture of C5 while travelling in the front seat of a car on 3 February 1994. On admission to another hospital, there was a deterioration in his neuro- logical level to C3 and respiratory arrest occurred. He was intubated and ventilated and had a tracheostomy. Chest infection developed managed by chest physiotherapy and parenteral antibiotics. He did not receive terbutaline nebuliser. On admission to the Mersey Regional Spinal Injuries Centre on 1 March 1994, his blood pressure was $128 / 70 \mathrm{~mm} \mathrm{Hg}$, heart rate 58 per min; and there was a sacral pressure sore. University of Virginia skull traction tongs were applied with $5 \mathrm{lb}$ weight. $\mathrm{He}$ had chest physio- therapy, and on 9 March 1994 nebulised terbutaline therapy}

using $2.5 \mathrm{mg}$ terbutaline in $4 \mathrm{ml}$ physiological saline, administered with the Uni-Mist drug nebuliser (Unimed UK Ltd, Unimed House, Shaftesbury, UK). There was immediate hypotension (brachial blood pressure dropped to $80 / 40$ $\mathrm{mm} \mathrm{Hg}$ from 124/70). There was no clinical evidence of impaired body fluid volume; no evidence of bacteraemia; and the urine output during the preceding $12 \mathrm{~h}$ was $>80$ $\mathrm{mlh}^{-1}$. One litre of physiological saline was given intravenously, and the blood pressure rose to $107 / 60 \mathrm{~mm} \mathrm{Hg}$. On 11 March 1994, he again received terbutaline as before, after confirming that body fluid volume had been restored. On this occasion also, there was no evidence of bacteraemia, and the urine output during the preceding $8 \mathrm{~h}$ was $>80 \mathrm{ml} \mathrm{h}^{-1}$. Immediately after the administration of the terbutaline his blood pressure dropped from $120 / 50 \mathrm{~mm} \mathrm{Hg}$ to $80 / 44 \mathrm{~mm} \mathrm{Hg}$ and his heart rate increased from 60 per min to 110 per min. He received a rapid intravenous infusion of 1 litre of physiological saline; the blood pressure remained about $80 / 40 \mathrm{~mm} \mathrm{Hg}$ for $30 \mathrm{~min}$, therefore he was given $500 \mu \mathrm{g}$ of phenylephrine slowly intravenously, resulting in an increase in the blood pressure to $230 / 90 \mathrm{~mm} \mathrm{Hg}$. He was immediately given $5 \mathrm{mg}$ nifedipine sublingually and his clinical condition stabilised without any sequelae. Clinical examination revealed complete flaccid tetraplegia at $\mathrm{C} 3$ level and absent deep tendon reflexes. The bulbocavernous reflex was present and pupils were equal and reacted normally to light. There was no sweating of face or neck. $\mathrm{He}$ was weaned off the ventilator gradually from 30 April 1994 onwards and off completely from 8 May 1994. Following his recovery from spinal shock he was given terbutaline nebuliser therapy as before, and there was no significant decrease in the arterial blood pressure. Since then he has been receiving terbutaline nebuliser therapy as and when required, with no adverse effects.

\section{Discussion}

Pingleton et $\mathrm{l}^{4}$ reported severe hypotension after the subcutaneous administration of $0.5 \mathrm{mg}$ terbutaline in two tetraplegic patients at $\mathrm{C} 4$ and $\mathrm{C} 5$ levels respectively. The former patient was treated in the Trendelenberg position with intravenous fluids; and the latter 
required dopamine infusion therapy for severe hypotension $(60 / 20 \mathrm{~mm} \mathrm{Hg})$. Both patients subsequently received one-half of their original dose of terbutaline ( $0.25 \mathrm{mg}$ given subcutaneously) after a $24 \mathrm{~h}$ stabilisation period. Haemodynamic measurements revealed a significant fall in systemic vascular resistance coincident with the drop in blood pressure. All parameters returned to normal within $2 \mathrm{~h}$. In our patient reported here, there was a significant fall in blood pressure with terbutaline nebuliser therapy administered during the spinal shock phase. It was corrected by rapid administration of physiological saline on the first occasion. During the second hypotensive episode, he required intravenous phenylephrine as the hypotension persisted even after intravenous administration of 1 litre of normal saline. However, there was no significant hypotension when terbutaline was administered 9 weeks later, by which time he had recovered from spinal shock. The explanation for the hypotension occurring after terbutaline nebuliser therapy is that the systemic vascular resistance was already low during the spinal shock phase and the administration of terbutaline by a nebuliser caused a further lowering of systemic vascular resistance to a level where the increase in heart rate and cardiac index were not fully able to compensate, thus resulting in a precipitous fall in blood pressure. There was no disturbance of the neurological condition of the patients during the period of hypotension.

This patient probably represents the first report of severe hypotension after terbutaline nebuliser therapy in a traumatic tetraplegic patient. It is not the nebulised form of delivery, but the drug itself which causes the hypotension. If the same drug (or similar drug) was given rectally, subcutaneously or intravenously, then the complication of hypotension would have occurred. As the nebuliser is the common method of administration of terbutaline to traumatic tetraplegics, the physician caring for spinal cord injured patients should bear in mind that terbutaline administration to such patients during the spinal shock phase may result in profound hypotension. It is prudent to monitor the cardiovascular status of traumatic tetraplegics when they receive terbutaline nebuliser therapy during the spinal shock phase.

\section{Acknowledgement}

Our gratitude goes to Jacqueline Stevens for her invaluable help in the preparation of this manuscript.

\section{References}

1 Mathias CJ, Frankel JL. Autonomic disturbances in spinal cord lesions. Bannister R, Mathias CJ. Autonomic Failure. A Textbook of Clinical Disorders of the Autonomic Nervous System. 3rd edn. Oxford University Press: Oxford, 1992, pp 839-881.

2 Meyer GA, Berman JR, Doty DB. Hemodynamic responses to acute quadriplegia with and without chest trauma. J Neurosurg 1971; 34: 168-177.

3 Burnell RH, Maxwell GM. The cardiovascular effects of terbutaline. Eur J Pharmacol 1971; 15: 383-385.

4 Pingleton SK, Schwartz O, Szymanski D, Epstein M. Hypotension associated with terbutaline therapy in acute quadriplegia. A report of two cases. Am Rev Respir Dis 1982; 126: 723-725. 